\title{
Is rolandic epilepsy really benign?
}

\section{Epilepsia rolândica é realmente benigna?}

Eliana Garzon

Seção de Eletroencefalografia, Hospital das Clínicas, Faculdade de Medicina, Universidade de São Paulo, Sao Paulo SP, Brazil.

\section{Correspondence:}

Eliana Garzon; Rua Barata Ribeiro 490, $11^{\circ}$ andar / cj. 117; 01308-000 São Paulo SP, Brasil; E-mail: egarzon@uol.com.br Conflict of interest:

There is no conflict of interest to declare.

Received 19 September 2014 Accepted 26 September 2014

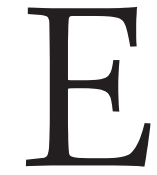
pilepsies can be considered as benign as long as they do not compromise the longterm quality of life of the person. Benign epilepsy with centrotemporal spikes (BECTS) or rolandic epilepsy (RE) is usually considered as a good example of this situation. RE has a number of clinical and electroencephalography (EEG) features that indicate a favourable outcome.

Classically, RE is described as partial epilepsy of childhood characterized by absence of neurological deficits, motor partial seizures, peculiar EEG centrotemporal spikes and spontaneous recovery. There are also children with peculiar EEG centrotemporal spikes with no clinical seizure, called EEG traits for RE.

Although $\mathrm{RE}$ is considered a benign syndrome and, in theory, with no neurological impairment, children with RE may have neuropsychological problems more often than the general population ${ }^{1}$. Even if neuropsychological involvements are considered as mild, the impact of $\mathrm{RE}$ on cognitive functions is far from being negligible ${ }^{2}$.

Delayed speech and learning disabilities have been reported, but their incidence and the long-term impact remains undetermined. The basic mechanism of cognitive compromise, in this syndrome, also remains unclear. It is difficult to determine, whether the deficits are due to the basic brain dysfunction responsible for the epilepsy, or to other factors such as, the effects of ongoing epileptic activity on developing cognitive functions.

Neuropsychological studies of children with RE show that they have normal intelligence but often have limited weaknesses in various domains such as language, visuospatial abilities or isolated attendant problems.

Some studies tried to demonstrate that cognitive disorders, which can occur in RE, could be temporary and more evident in the active phase of the disease. These studies seem to correlate cognitive disorders with an increase in epileptic activity during this period. Attempts to correlate these deficits with the frequency of clinical seizures and with the side of discharges, for example, left or right side, unilateral or bilateral foci, have given conflicting results ${ }^{3,4}$.

On the other hand, when EEGs of children with dyslexia were analyzed, $10 \%$ showed EEG traits of $\mathrm{RE}^{5}$. Ten per cent means 2-5 times higher than the expected rate that is estimated to be about $2-4 \%$ in the child population ${ }^{6}$. The results raise a number of questions about the relationship between dyslexia and a specific EEG trait and RE and language or any other neuropsychological impairment.

Other interesting point is that language disabilities and academic impairments found in $\mathrm{RE}$ are also common in relatives of RE probands. The incidence of language, reading disabilities and academic impairments in relatives of RE probands are 5.4 times that in the general population?

The strong proband and familial associations with reading disabilities and academic impairments and the similarity in neurocognitive profiles between probands and siblings, suggest that these neurodevelopmental traits in RE should be also genetically influenced ${ }^{8}$.

The role of genetic influences has been sought for a long time. The hypothesis of shared genetic influences, recently has been demonstrated as a familial pattern of risk for reading disability, speech sound disorder, presence of EEG traits of RE, and migraine in families with $\mathrm{RE}^{9,10,11,12,13}$.

These results strongly suggest that susceptibility to comorbidities in $\mathrm{RE}$ is inherited and not the direct result of recurrent seizures or discharges. Clinically, relevance of these studies is that early evaluation and intervention may benefit these children academically. 
Long-term neuropsychological evaluation showed that neurocognitive impairments remain even after seizure remission, suggesting a persistent course that does not correlate with the time course of either seizures or EEG abnormality in $\mathrm{RE}^{14}$, although the seizures and EEG abnormality may well complicate neurocognitive performance, as suggested by the association of attendant impairment and centrotemporal spikes ${ }^{15}$.

Besides genetic evaluation, scans with functional MRI using word-generation and reading tasks in children with $\mathrm{RE}$ has been done comparing age-matched controls. Data has shown that functional connectivity with the sensorimotor network was reduced in patients with $\mathrm{RE}$ compared to controls. Reduced functional connectivity was demonstrated between the sensorimotor network and the left inferior frontal gyrus, Broca's area, in children with RE. These findings might link epileptiform activity originating from the sensorimotor cortex to language impairment ${ }^{16}$.

Structural scans using T1-weighted and diffusionweighted MRI at 3T and corresponding research has shown that in RE, structural connectivity is reduced for several connections involving rolandic regions, from which the epileptiform activity originates. Most of these aberrant tracts involve the left hemisphere, especially the pars opercularis of the inferior frontal gyrus (Broca's area) and the supramarginal gyrus ${ }^{17}$.

Although the underlying mechanism may be multiple, the accurate diagnosis of comorbid conditions is of great importance for research, pathophysiology comprehension and for clinical prognosis and a better approach.

In this fascinating scenario that Oliveira EP et al., ${ }^{18}$ authors of rolandic epilepsy and dyslexia, a paper published in this number of Arquivos de Neuro-Psiquiatria, studied the prevalence of dyslexia and other language impairments in a group of 31 patients with clinical and electrographically diagnosis of RE. What stands out in this study is the detailed clinical and neuropsychological assessment that allowed the authors to diagnose dyslexia. The choice of control group is of fundamental importance. If there is a probability of relatives being affected by epileptiform discharges at centrotemporal regions or by comorbidities, including language impairments, relatives would not be the appropriate control group for later comparison of data. In this paper, the control group was recruited from regular schools.

Oliveira et al. findings show significant evidence for occurrence of dyslexia in patients with RE. Out of 31 patients, six (19.4\%) had a diagnosis of dyslexia. Dyslexia diagnosis is not so simple to assume and in this paper, the authors showed that a detailed evaluation was necessary for a precise diagnosis. The main finding of their study contributes significantly to understanding school performance of children with RE. The findings are extremely important for patient rehabilitation.

Beyond the rehabilitation of the patient, their results allow and encourage future studies in several aspects, including clinical and neuropsychological long-term evolution, which are scarce in the literature.

\section{References}

1. Deonna T. Rolandic epilepsy: neuropsychology of the active epilepsy phase. Epileptic Disord. 2000;2 Suppl 1:S59-66.

2. Lerman P, Kivity S. Benign focal epilepsy of childhood. A follow-up of 100 recovered patients. Arch Neurol. 1975;32(4):261-4. http://dx.doi.org/10.1001/archneur.1975.00490460077010

3. Metz-Lutz MN, Kleitz C, Saint Martin A, Massa R, Hirsch E, Marescaux C. Cognitive development in benign focal epilepsies of childhood. Dev Neurosci. 1999;21(3-5):182-90. http://dx.doi.org/10.1159/ 000017397

4. D’Alessandro P, Piccirilli M, Tiacci C, Ibba A, Maiotti M, Sciarma T et al. Neuropsychological features of benign partial epilepsy in children. Ital J Neurol Sci. 1990;11(3):265-9. http://dx.doi.org/ 10.1007/BF02333856

5. Carlsson G, Igelbrink-Schulze N, Neubauer BA, Stephani U. Neuropsychological long-term outcome of rolandic EEG traits. Epileptic Disord. 2000;2 Suppl 1:S63-6.

6. Eeg-Olofsson O, Petersén I, Selldén U. The development of the electroencephalogram in normal children from the age of 1 through 15 years. Paroxysmal activity. Neuropadiatrie. 1971;2(4):375-404. http://dx.doi.org/10.1055/s-0028-1091791

7. Clarke T, Strug LJ, Murphy PL, Bali B, Carvalho J, Foster S et al. High risk of reading disability and speech sound disorder in rolandic epilepsy families: case-control study. Epilepsia. 2007;48(12):2258-65. http://dx.doi.org/10.1111/j.1528-1167.2007.01276.x
8. Smith AB, Kavros PM, Clarke T, Dorta NJ, Tremont G, Pal DK. A neurocognitive endophenotype associated with rolandic epilepsy. Epilepsia. 2012;53(4):705-11. http://dx.doi.org/10.1111/j.1528-1167. 2011.03371.x

9. Bali B, Kull LL, Strug LJ, Clarke T, Murphy PL, Akman Cl et al. Autosomal dominant inheritance of centrotemporal sharp waves in rolandic epilepsy families. Epilepsia. 2007;48(12):2266-72. http://dx.doi.org/10.1111/j.1528-1167.2007.01221.x

10. Clarke T, Baskurt Z, Strug LJ, Pal DK. Evidence of shared genetic risk factors for migraine and rolandic epilepsy. Epilepsia. 2009;50(11):2428-33.

11. Pal DK, Li W, Clarke T, Lieberman P, Strug LJ. Pleiotropic effects of the $11 \mathrm{p} 13$ locus on developmental verbal dyspraxia and EEG centrotemporal sharp waves. Genes Brain Behav. 2010;9(8):1004-12. http://dx.doi.org/10.1111/j.1601-183X.2010.00648.x

12. Strug LJ, Addis L, Chiang T, Baskurt Z, Li W, Clarke T et al. The genetics of reading disability in an often excluded sample: novel loci suggested for reading disability in rolandic epilepsy. PLoS ONE. 2012;7(7):e40696. http://dx.doi.org/10.1371/journal. pone.0040696

13. Addis L, Chiang T, Clarke T, Hardisson H, Kugler S, Mandelbaum DE et al. Evidence for linkage of migraine in rolandic epilepsy to known 1q23 FHM2 and novel 17q22 genetic loci. Genes Brain Behav. 2014;13(3):333-40. http://dx.doi.org/10.1111/gbb.12110 
14. Hommet C, Billard C, Motte J, Passage GD, Perrier D, Gillet P et al. Cognitive function in adolescents and young adults in complete remission from benign childhood epilepsy with centro-temporal spikes. Epileptic Disord. 2001;3(4):207-16.

15. Strug LJ, Clarke T, Chiang T, Chien M, Baskurt Z, Li W et al. Centrotemporal sharp wave EEG trait in rolandic epilepsy maps to Elongator Protein Complex 4 (ELP4). Eur J Hum Genet. 2009;17(9):1171-81. http://dx.doi.org/10.1038/ejhg.2008.267

16. Besseling RM, Jansen JF, Overvliet GM, Kruijs SJ, Vles JS, Ebus SC et al. Reduced functional integration of the sensorimotor and language network in rolandic epilepsy. Neuroimage Clin. 2013;2(2):239-46. http://dx.doi.org/10.1016/j.nicl.2013.01.004

17. Besseling RM, Jansen JF, Overvliet GM, Kruijs SJ, Ebus SC, Louw A et al. Reduced structural connectivity between sensorimotor and language areas in rolandic epilepsy. PLoS ONE. 2013;8(12):e83568. http://dx.doi.org/10.1371/journal.pone.0083568

18. Oliveira EP, Neri ML, Capelatto LL et al. Rolandic epilepsy and dyslexia. Arq Neuropsiquiatr. 2014;72(11):826-31. http://dx.doi.org/ 10.1590/0004-282X20140141 